Correlates of In-Store Promotions for Beer: Differential Effects of Market and Product $\underline{\text { Characteristics }}$

By: Jeremy W. Bray, Brett Loomis, and Mark Engelen

Bray, J. W., Loomis, B. R., \& Engelen, M. A. (2007). Correlates of in-store promotions for beer: Differential effects of market and product characteristics. Journal of Studies on Alcohol and Drugs, 68(2), 220-227.

Made available courtesy of Rutgers Center of Alcohol Studies: http://www.jsad.com/.

***@ C Rutgers Center of Alcohol Studies. Reprinted with permission. No further reproduction is authorized without written permission from Rutgers Center of Alcohol Studies. This version of the document is not the version of record. Figures and/or pictures may be missing from this format of the document.

\begin{abstract}
:
Objective: We estimated the strength and direction of the association between product characteristics (beer type, package size, and brand name) and market-area socioeconomic characteristics, and promoted sales of beer in grocery stores. Method: Supermarket scanner data from 64 market areas across the United States over 5 years were used to estimate regression models of the share of beer sales that are promoted, controlling for beer price, packaging, and type; and for market-level age, race/ethnicity, income, unemployment rate, and percentage of the population living in an alcohol control state. Results: Large-volume units, such as 144-oz and 288-oz packages, are more likely to be promoted than smaller package sizes. Malt-liquor beverages are less likely to be promoted than non-malt-liquor beverages. Age, race/ ethnicity, income, and geographic location of the market area are not significantly related to promoted beer sales. Conclusions: Marketing research has shown that in-store merchandising and promotions can substantially increase beer sales and that purchasing large package sizes may increase total consumption. Our results suggest that high levels of promoted sales for large-volume beer packages may result in increased beer consumption.
\end{abstract}

Keywords: market-area socioeconomic characteristics | beer | promoted sales | supermarket scanner data

Article:

***Note: Full text of article below 


\title{
Correlates of In-Store Promotions for Beer: Differential Effects of Market and Product Characteristics*
}

\author{
JEREMY W. BRAY, PH.D., ${ }^{\dagger}$ BRETT LOOMIS, M.S., AND MARK ENGELEN, B.S., B.A. \\ RTI International, 3040 Cornwallis Road. P.O. Box 12194, Research Triangle Park, North Carolina 27709
}

\begin{abstract}
Objective: We estimated the strength and direction of the association between product characteristics (beer type, package size, and brand name) and market-area socioeconomic characteristics, and promoted sales of beer in grocery stores. Method: Supermarket scanner data from 64 market areas across the United States over 5 years were used to estimate regression models of the share of beer sales that are promoted, controlling for beer price, packaging, and type; and for market-level age, race/ethnicity, income, unemployment rate, and percentage of the population living in an alcohol control state. Results: Large-volume units, such as $144-\mathrm{oz}$ and $288-\mathrm{oz}$ packages, are more
\end{abstract}

likely to be promoted than smaller package sizes. Malt-liquor beverages are less likely to be promoted than non-malt-liquor beverages. Age, race/ ethnicity, income, and geographic location of the market area are not significantly related to promoted beer sales. Conclusions: Marketing research has shown that in-store merchandising and promotions can substantially increase beer sales and that purchasing large package sizes may increase total consumption. Our results suggest that high levels of promoted sales for large-volume beer packages may result in increased beer consumption. (J. Stud. Alcohol Drugs 68: 220-227, 2007)
A LCOHOL MISUSE, ABUSE, AND DEPENDENCE are associated with many behavioral and social problems, including domestic violence and homicide (National Institute on Alcohol Abuse and Alcoholism, 2000), traffic fatalities (National Institute on Alcohol Abuse and Alcoholism, 1994), and chronic health problems (National Institute on Alcohol Abuse and Alcoholism, 1994). Alcohol consumption is the third leading cause of preventable death in the United States (McGinnis and Foege, 1993; Mokdad et al., 2004), and in 2001 excessive alcohol consumption was responsible for an estimated 75,766 deaths (Midanik et al., 2004). Despite these negative consequences, alcohol is widely marketed and promoted.

Beverage manufacturers spent more than $\$ 2$ billion on advertising and promotion efforts in 1999 (Alaniz and Wilkes, 1998; FTC, 1999). Point-of-purchase (POP) advertising, in particular, is a popular and cost-effective method that product manufacturers use to reach consumers and in-

Received: May 19, 2006. Revision: October 9, 2006.

* Partial support was provided by Robert Wood Johnson Foundation Substance Abuse Policy Research Program (RWJF SAPRP) grant 052446 and by National Institute on Alcohol Abuse and Alcoholism (NIAAA) grants 1R01-AA12788 and R01-AA013925-03. This article does not represent the policies or the positions of the RWJF SAPRP or the NIAAA. No official endorsement by either of these organizations is intended or should be inferred. The authors have no financial or personal relationships that constitute a conflict of interest for this research.

${ }^{+}$Correspondence may be sent to Jeremy Bray at the above address or via email at: bray@rti.org. crease sales. POP alcohol advertising can be found in nearly $90 \%$ of stores that sell alcohol (Terry-McElrath et al., 2003) and includes price discounts, displays, product placement, signage, in-store circulars, and other on-site merchandising. A study by the Point of Purchase Association International, a trade association of the POP advertising industry, showed that beer sales in supermarkets increased by between $2.9 \%$ and $17 \%$ in the presence of POP advertising (Beverage Industry Magazine, 2001).

Alcohol producers and retailers are thought to target advertising differentially along age and race/ethnicity dimensions. Minority and low-income neighborhoods generally have a higher density of alcohol outlets than white and higher-income neighborhoods and therefore have greater alcohol availability (Alaniz, 1998). Alcohol availability is positively correlated with alcohol-related problems, such as alcoholism, drunk-driving fatalities, and violence (Alaniz, 1998; Scribner et al., 1995, 1999; Zhu et al., 2004). Minority neighborhoods are also subject to greater amounts of alcohol advertising on billboards (Hackbarth et al., 1995). Alcohol outlet densities are higher and alcohol promotions are more prevalent around some college campuses than in other similar neighborhoods and are associated with higher than average heavy episodic drinking rates among college students (Kuo et al., 2003; Weitzman et al., 2003a,b).

Despite evidence suggesting that age, race/ethnicity, and economic characteristics of neighborhoods are important correlates of alcohol-outlet density and advertising, little is known about how these characteristics relate to the use of in-store promotions. Little is also known about how in-store 
promotions correlate with product characteristics. In perhaps the only study to examine the relationship between community characteristics and in-store promotions, Harwood et al. (2003) used a national cross-section of 2,024 retailers from 160 communities in 2000 to examine the extent of pricing and in-store promotions for 6-packs of Budweiser and Miller beer. They concluded that pricing and in-store promotions do not target racial minority populations. However, because Harwood et al. collected data only on 6-packs of Budweiser and Miller beer, they were unable to assess the relationship between in-store promotions and beer type (e.g., malt liquor) or packaging (e.g., 6-packs vs 12-packs).

In this study, we used scanner data collected in supermarkets across the United States from 1995 through 1999 to examine the association between product and market socioeconomic characteristics and promoted sales of more than 250 brands of beer.

\section{Method}

\section{Scanner data}

The primary data for these analyses were InfoScan Retail Tracking data, licensed from Information Resources Incorporated (IRI; IRI, 2000). These scanner data were collected from supermarkets in 64 retail market areas in the United States and reported for each calendar quarter from 1995 through 1999. Supermarkets are defined by IRI as large grocery stores having at least \$2 million in annual sales, or about $\$ 5,500$ a day. We focus on supermarkets because they capture almost as much of the market for beer $(40 \%)$ as convenience stores $(23 \%)$ and liquor stores $(21 \%)$ combined (National Association of Convenience Stores, 2004). Also, discussions with IRI revealed that convenience and liquor stores have relatively low scanner penetration compared with supermarkets. This means that many such outlets do not have scanner technology in them at all or only rudimentary systems that are not useful for collecting and storing detailed information on sales. Thus, a low participation rate exists for convenience and liquor stores with scanner data collectors such as IRI. Independently owned liquor stores, in particular, have near-zero participation rates.

The IRI supermarket data are reported for individual beer varieties, which are identified with a universal product code (UPC) and an associated item description. Data are reported for 257 beer brands. The item description includes codes for brand name (e.g., Budweiser), beer type (e.g., malt liquor, nonalcoholic, ale, lager), packaging (e.g., cans in a box), and unit size in ounces. The data were limited in that they did not report all beer varieties sold in 1999; they reported only the 100 most popular varieties (ranked by unit sales) in each market. For each variety, total unit sales, the proportion of total units sold under a promotion, and average price per unit were reported for each of the 64 market areas in each calendar quarter. IRI defines promoted sales as all sales of a specific UPC that occur in a store that has any form of merchandising or in-store promotion for that UPC. In-store promotions may include product features, displays, branded signs, and price reductions. IRI does not, however, aggregate sales data by type of promotion.

Each retail market is a collection of counties centered on a metropolitan area. Combined, these areas captured approximately $72 \%$ of the U.S. population from 1995 through 1999. Markets contained an average of 15 counties (range: $1-78$, median $=9$ ). The average market population was 3.1 million (range: $367,000-18.7$ million, median $=2.5$ million).

\section{Measures}

The dependent variable used in these analyses was the percentage of units sold in the presence of any promotion or merchandising in supermarkets. We constructed 10 independent predictor variables from the scanner data that captured packaging, type, and price characteristics of the beer varieties. Using census data, we constructed 14 independent predictor variables that measured the demographic and economic characteristics of the market areas. Other control variables in the analysis were indicators for beer brand, year, and census region where the market is located.

Beer characteristics. Preliminary analysis of the data revealed four primary packaging sizes: $40-\mathrm{oz}$ packages that correspond to single $40-\mathrm{oz}$ bottles; $72-\mathrm{oz}$ packages that correspond to a 6-pack of $12-\mathrm{oz}$ beers; $144-\mathrm{oz}$ packages that correspond to a 12-pack of $12-\mathrm{oz}$ beers; and 288-oz packages that correspond to a 24-pack of $12-\mathrm{oz}$ beers (i.e., a case). In addition to these sizes, the data contained numerous other sizes, each occurring with relatively low frequency. Based on this data pattern, we created six indicators for the size, in ounces, of the beer variety as follows: (1) an indicator for 40-oz packages; (2) an indicator for all packages of less than $72 \mathrm{oz}$, excluding 40 -oz packages; (3) an indicator for 72-oz packages; (4) an indicator for 144-oz packages; (5) an indicator for 288-oz packages; and (6) an indicator for all packages of more than $72 \mathrm{oz}$, excluding $144-\mathrm{oz}$ and 288 -oz packages. The reference category in the analysis is 72-oz packages, which corresponds to a standard 6-pack of 12-oz beers.

We created three indicators for beer type: malt liquor, nonalcoholic, and standard alcoholic beer (e.g., lager, ale, pilsner). The reference category is standard alcoholic beer. We also created a variable that measured the price per 72 $\mathrm{oz}$ for each beer variety. For example, if a $288-\mathrm{oz}$ package cost $\$ 12$, then the price per $72-\mathrm{oz}$ volume was $\$ 3$ for that particular variety.

Demographic and economic characteristics of markets. To measure the socioeconomic conditions within the scanner-data markets, we used population data from the Bureau of the Census (2000), income data from the Bureau of 
Economic Analysis (1995-1999), and economic data from the Bureau of Labor Statistics (1995-1999). For all three data sources, market-level measures were calculated from county-level data. Data from the Bureau of the Census and from the Bureau of Economic Analysis were annual data measured as of the third quarter of the relevant year. Therefore, demographic and economic variables were merged to the scanner markets in the third quarter of each year from 1995 through 1999. We created variables that measured the proportion of the market population in four age groups: up to 11 years old, 12-17 years, 18-24 years, and 25 years and older (reference category). Although census data include information on non-Hispanic whites, African Americans, Hispanics, American Indians and Alaska Natives, and Asians and Pacific Islanders, preliminary multivariate analyses on the percentage of units sold under a promotion indicated that all racial categories other than non-Hispanic white could be combined into a single category. Therefore, two variables were created to measure the race/ethnicity of each market: the proportion of the population that is minority (i.e., nonwhite) and the proportion that is white (reference category).

Economic variables were average per capita income, average per capita income squared, and unemployment rate. Average per capita income squared was included to allow for a potentially nonlinear relationship between beer promotions and income.

Much of the previous literature on the relationship between alcohol promotions and race or age has been done at the census-block or zip-code level (e.g., Alaniz, 1998; Hackbarth et al., 1995; Kuo et al., 2003; Weitzman et al., 2003a,b). This literature raised a concern that our marketlevel measures of race and age may fail to identify any targeting of minorities or youth that occurs in smaller geographic areas within a market. Of course, if any given group of minorities or youth is targeted, then that group's community or neighborhood is also targeted, as is its market. The problem is not that the targeting of minorities or youth is obscured by aggregation to the market level but that not all minority or youth markets may be targeted. Targeting of minority or youth markets may require not just prevalence of the targeted group but also definable submarkets that have a very high concentration of the targeted population. That is, the market must be residentially segregated in terms of the evenness of the racial or youth spatial distribution.

To allow the spatial distribution of the population within the market areas to affect promoted beer sales independently from the population proportions, we calculated spatial segregation indices. Indices were created for people between the ages of 18 and 24 (i.e., college-age adults) and for whites, blacks, and Hispanics within each market using the dissimilarity index (Massey and Denton, 1988). The dissimilarity index is a widely used measure of residential evenness that measures the proportion of a population group that would have to move from one county to another to achieve an even spatial distribution within the market. The index ranges from 0 , indicating no segregation, to 1 , indicating complete segregation.

Finally, we calculated the percentage of the market population living in an alcohol control state by summing the population of the counties in an alcohol control state and dividing by the total population of the market. Alcohol control states have state monopoly over the wholesaling, retailing, or both of some or all categories of alcoholic beverages. Alcohol control states were identified using the online Alcohol Policy Information System (2005) from the National Institute on Alcohol Abuse and Alcoholism and online resources of the National Alcohol Beverage Control Association (2005). The alcohol control states were Alabama, Idaho, Iowa, Maine, Michigan, Mississippi, Montana, New Hampshire, North Carolina, Ohio, Oregon, Pennsylvania, Utah, Vermont, Virginia, Washington, West Virginia, and Wyoming. Of the 60 markets used in our analyses, 36 were contained completely within a noncontrol state, and 15 were contained completely within a control state. Of the remaining nine markets (all of which spanned multiple states), four had more than $58 \%$ of their population within a control state, and five had less than $12 \%$ within a control state.

Fixed effects. Indicator variables were created for each standard alcoholic beer brand (e.g., Budweiser, Bud Light, Heineken) to control for time-invariant brand-specific effects that are correlated with promoted sales, such as brand loyalty and brand image. Because few malt-liquor brands appear in the data, these brands were not identified with individual indicator variables. Instead, these brand effects were grouped together in the malt-liquor indicator and thus were treated as a single type. Similarly, there were few nonalcoholic brands in the data; therefore, they were grouped together in the nonalcoholic indicator. Each market was assigned to one of four census regions (i.e., West, Midwest, Northeast, and South), and an indicator was created for each region, with South as the reference category. Finally, indicators were created for year to control for changes over time, with 1995 as the reference year.

\section{Statistical analyses}

Because the dependent variable (i.e., $p=$ percentage of units sold under a promotion) is bounded between 0 and 1 , we transformed the dependent variable using the logit transformation, $\operatorname{logit}(p)=\log [p /(1-p)]$, before estimation by weighted least squares (Greene, 1997; Maddala, 1983). Standard errors were calculated using the robust Huber/White/ Sandwich variance estimator to account for the correlation across observations within a market. The variance estimation procedure allows for observations on sales to be correlated (i.e., clustered) within markets but assumes independence 
across markets. All models were estimated using the regress command in Stata version 8.2 (StataCorp, College Station, TX), with appropriate weights and the cluster (market) option.

Population data were available from the census only in the third quarter of each year. Accordingly, we used only the third-quarter observations of the scanner data in the multivariate analyses and in univariate analyses of market characteristics. Data from all 20 quarters were used in the univariate analyses of product characteristics.

We excluded three Pennsylvania markets (Harrisburg, Philadelphia, and Pittsburgh) because Pennsylvania prohibits the sale of alcoholic beer in grocery stores; therefore, all beer sales reported in Pennsylvania markets were nonalcoholic. We also excluded the Providence, RI, market because all beer sales in that market were nonalcoholic. Although Rhode Island is not an alcohol control state, it is a strict licensure state, and grocery stores could not obtain licenses to sell alcoholic beer over the period covered by our data. Because Pennsylvania and Rhode Island have restricted beer sales in supermarkets to the extent that no sales of alcoholic beer occurred in supermarkets, they potentially are structurally different from all other markets in our data with respect to sales and promotions of alcoholic beer in supermarkets. Furthermore, they account for only $1 \%$ of observations. We therefore excluded them from our analyses.
The San Diego, CA, market consists of a single county, prohibiting calculation of segregation indices for that market. To keep San Diego in the models, we set the segregation indices for San Diego to zero and introduced an indicator variable for the San Diego market.

\section{Results}

\section{Univariate analyses}

Using data from all 20 quarters, the percentage of beer sales in supermarkets occurring under an in-store promotion is shown in Figure 1. Except for 1999, promoted sales appear to be seasonal, with the second (April-June) and third (July-September) calendar quarters generally having the highest percentages of promoted sales and the first quarter (January-March) having the lowest. Except for this potential seasonality, the percentage of beer sales that were promoted was fairly constant from 1995 through 1999, averaging $35 \%$ of total beer sales. However, the trend appeared to fall and become less seasonal in 1999. Results from the multivariate analyses (reported in the following) show that the decrease in 1999 is not statistically significant but that there is a significant increase in 1997.

Table 1 presents information on the socioeconomic characteristics of the markets in our data. We averaged all quarterly observations on markets to obtain a single observation

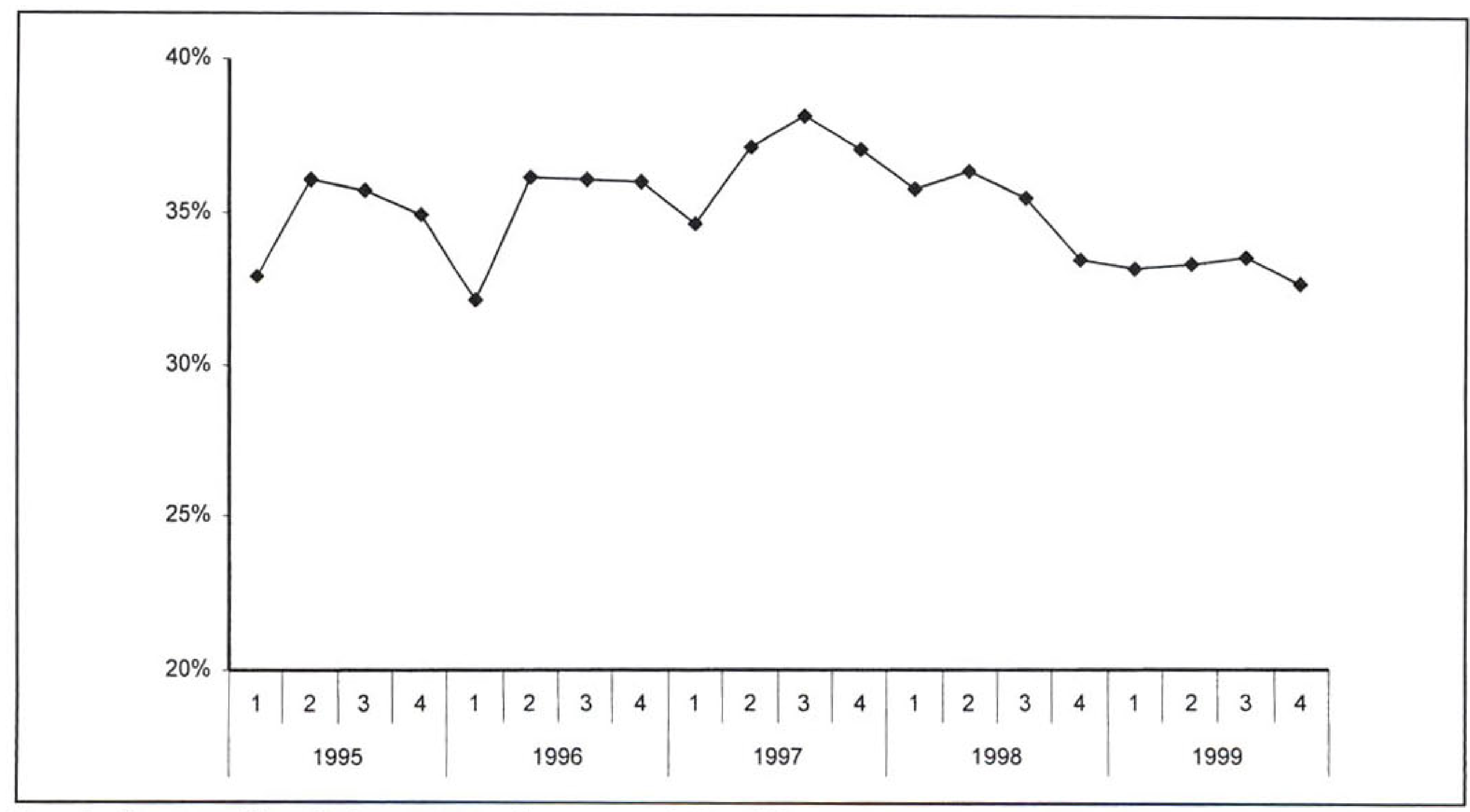

Figure 1. Percentage of beer sales in grocery stores that are promoted, 1995-1999 
TABLE 1. Univariate analyses: Distribution of socioeconomic characteristics and proportion of beer sales sold under a promotion

\begin{tabular}{|c|c|c|}
\hline $\begin{array}{l}\text { Market characteristic } \\
\text { (quartile) }\end{array}$ & Estimate & $\begin{array}{l}\text { Percentage of sales } \\
\text { that are promoted }\end{array}$ \\
\hline \multicolumn{3}{|l|}{$\overline{\text { Percentage minority }}$} \\
\hline 25 th & $13.2 \%$ & $38.7 \%$ \\
\hline Median & $20.6 \%$ & $40.4 \%$ \\
\hline 75 th & $35.0 \%$ & $39.3 \%$ \\
\hline \multicolumn{3}{|c|}{ White dissimilarity index } \\
\hline 25 th & 0.176 & $33.2 \%$ \\
\hline Median & 0.272 & $37.6 \%$ \\
\hline 75 th & 0.304 & $41.8 \%$ \\
\hline \multicolumn{3}{|c|}{ Black dissimilarity index } \\
\hline 25 th & 0.206 & $35.2 \%$ \\
\hline Median & 0.294 & $34.3 \%$ \\
\hline 75 th & 0.361 & $37.6 \%$ \\
\hline \multicolumn{3}{|c|}{ Hispanic dissimilarity index } \\
\hline 25 th & 0.123 & $34.6 \%$ \\
\hline Median & 0.169 & $25.9 \%$ \\
\hline 75 th & 0.251 & $27.5 \%$ \\
\hline \multicolumn{3}{|l|}{ Percentage $<$ age 12} \\
\hline 25 th & $16.4 \%$ & $34.0 \%$ \\
\hline Median & $17.3 \%$ & $32.2 \%$ \\
\hline 75 th & $17.9 \%$ & $38.6 \%$ \\
\hline \multicolumn{3}{|l|}{ Percentage ages $12-17$} \\
\hline 25 th & $8.1 \%$ & $27.5 \%$ \\
\hline Median & $8.5 \%$ & $32.8 \%$ \\
\hline 75 th & $9.0 \%$ & $37.8 \%$ \\
\hline \multicolumn{3}{|l|}{ Percentage $<$ age 18} \\
\hline 25 th & $24.6 \%$ & $35.4 \%$ \\
\hline Median & $25.9 \%$ & $30.3 \%$ \\
\hline 75 th & $26.9 \%$ & $40.9 \%$ \\
\hline \multicolumn{3}{|l|}{ Percentage ages $18-24 \S$} \\
\hline 25 th & $8.9 \%$ & $29.2 \%$ \\
\hline Median & $9.7 \%$ & $34.7 \%$ \\
\hline 75 th & $10.4 \%$ & $30.3 \%$ \\
\hline \multicolumn{3}{|c|}{ Ages 18-24 dissimilarity index } \\
\hline 25 th & 0.041 & $30.9 \%$ \\
\hline Median & 0.073 & $32.8 \%$ \\
\hline 75 th & 0.092 & $33.7 \%$ \\
\hline \multicolumn{3}{|c|}{ Annual per capita income } \\
\hline 25 th & $\$ 23,415$ & $38.8 \%$ \\
\hline Median & $\$ 25,953$ & $37.3 \%$ \\
\hline 75 th & $\$ 28.138$ & $29.3 \%$ \\
\hline \multicolumn{3}{|l|}{ Unemployment rate ${ }^{\S}$} \\
\hline 25 th & $3.4 \%$ & $27.5 \%$ \\
\hline Median & $4.1 \%$ & $36.5 \%$ \\
\hline 75 th & $4.7 \%$ & $42.4 \%$ \\
\hline \multicolumn{3}{|c|}{$\begin{array}{l}\text { Percentage of the population in } \\
\text { an alcohol control state }\end{array}$} \\
\hline Noncontrol state & $0.0 \%$ & $35.5 \%$ \\
\hline Mixed & $0.0 \%-99.9 \%$ & $34.3 \%$ \\
\hline Control state & $100 \%$ & $35.3 \%$ \\
\hline
\end{tabular}

Notes: $N=60$.

$\$_{p}<.10$ based on analysis of variance testing.

per market, resulting in 60 observations. In addition, we used analysis of variance on these 60 observations to test for significant differences in the percentage of sales promoted across groups formed by the quartiles of each market characteristic. The first data column of Table 1 presents the 25 th percentile, median, and 75 th percentile of each market characteristic, and the second data column presents the associated proportion of beer sales that were promoted.
The table suggests a positive and marginally significant relationship between the proportion of beer sales that were promoted and the percentage of the market population that are minorities, the percentage of the market's population that is between 18 and 24 , and the market unemployment rate. None of the other socioeconomic characteristics measured appeared to be consistently associated with changes in the proportion of beer sales that were promoted.

Table 2 presents the distribution of total sales and promoted sales by package size, beer type, and brand (top five selling brands only). The table suggests that larger package sizes are associated with a greater proportion of promoted sales: $72-\mathrm{oz}$ packages accounted for $12 \%$ of total sales, with $27 \%$ of those sales promoted; $144-\mathrm{oz}$ packages, the most common units sold, accounted for $51 \%$ of sales, with $49 \%$ of those sales promoted; and 288-oz packages accounted for $19 \%$ of total sales, with $56 \%$ of those sales promoted. Package sizes larger than $72 \mathrm{oz}$ (excluding 144 and $288-\mathrm{oz}$ packages) captured only $16 \%$ of sales, but more than $61 \%$ of those sales were promoted. Combined, nonalcoholic and malt-liquor beers captured less than $2 \%$ of total beer sales in our data, but $25 \%$ of nonalcoholic sales and $20 \%$ of malt-liquor sales were promoted. Although the rate of promotion for nonalcoholic and malt-liquor beers is high relative to their market share, they are still promoted less than standard alcoholic beer, which had $36 \%$ of sales promoted. The top five selling brands of beer all have higher than average levels of promotional sales. The number-one brand, Budweiser, captured $16 \%$ of sales in our data from 1995 through 1999, and $59 \%$ of those sales were promoted.

TABLE 2. Univariate analyses: Distribution of sales and promoted sales, by package size, beer type, and selected brands

\begin{tabular}{lcc}
\hline Category & $\begin{array}{c}\text { Total sales accounted } \\
\text { for by category } \\
\%\end{array}$ & $\begin{array}{c}\text { Sales in category } \\
\text { that are promoted } \\
\%\end{array}$ \\
\hline $\begin{array}{c}\text { Package size } \\
<72 \mathrm{oz}^{\circ}\end{array}$ & 1.23 & \\
$40 \mathrm{oz}$ & 0.15 & 24.05 \\
$72 \mathrm{oz}$ & 12.43 & 11.95 \\
$144 \mathrm{oz}$ & 51.21 & 27.32 \\
$288 \mathrm{oz}$ & 19.44 & 49.20 \\
$>72 \mathrm{oz}^{b}$ & 15.53 & 56.26 \\
Beer type & & 61.58 \\
Nonalcoholic & 1.11 & \\
Malt liquor & 0.29 & 25.22 \\
Standard alcoholic & 98.6 & 20.40 \\
Top brands & & 35.5 \\
Budweiser & 16.24 & 59.40 \\
Bud Light & 13.84 & 60.12 \\
Miller Light & 9.51 & 61.94 \\
Coors Light & 9.00 & 55.93 \\
Natural Light & 5.47 & 32.72 \\
All others & 45.94 & 32.98 \\
\hline
\end{tabular}

Notes: $N=20,143,{ }^{a}$ Excluding $40 \mathrm{oz}$; ${ }^{b}$ excluding 144 and $288 \mathrm{oz}$.

${ }^{+} p<.01$ based on chi-square tests of association; no results significant at $p<.05$. 


\section{Multivariate analyses}

Table 3 presents results from the multivariate analysis of beer promotions. Large package sizes and malt liquors are significantly associated with promoted sales in supermarkets, whereas small package sizes, price, and nonalcoholic beer are not. Compared with 72-oz packages, all package sizes larger than $72 \mathrm{oz}$ are significantly more likely to be promoted, with the odds of a promoted sale increasing with package size. The odds ratio (OR) is $2.59(95 \%$ confidence interval [CI]: 2.28-2.94) for 144-oz packages, 3.44 (95\% CI: 2.63-4.50) for 288-oz packages, and 3.18 (95\% CI: 2.50-4.04) for all other package sizes larger than $72 \mathrm{oz}$. Compared with standard alcoholic beer, malt liquors are significantly less likely to be promoted $(\mathrm{OR}=0.49$, 95\% CI: 0.33-0.74).

TABLE 3. Grouped logistic regression results for promoted beer sales in grocery stores, 1995-1999

\begin{tabular}{|c|c|c|}
\hline Variable & $\begin{array}{c}\text { Logistic } \\
\text { coefficient (SE) }\end{array}$ & $\begin{array}{c}\mathrm{OR} \\
(95 \% \mathrm{Cl})\end{array}$ \\
\hline \multicolumn{3}{|l|}{ Product characteristics } \\
\hline $40 \mathrm{oz}^{a}$ & $-0.365(0.275)$ & ns \\
\hline$<72 \mathrm{oz}^{a}$ (except $\left.40 \mathrm{oz}\right)$ & $0.218(0.221)$ & ns \\
\hline $144 \mathrm{oz}^{a}$ & $0.951^{\dagger}(0.064)$ & $2.59(2.28-2.94)$ \\
\hline $288 \mathrm{oz}^{a}$ & $1.236^{\dagger}(0.134)$ & $3.44(2.63-4.5)$ \\
\hline$>72 \mathrm{oz}^{a}$ (except 144 and $\left.288 \mathrm{oz}\right)$ & $1.157^{\dagger}(0.12)$ & $3.18(2.5-4.04)$ \\
\hline Average price per volume & $-0.01(0.029)$ & ns \\
\hline Malt liquor ${ }^{b}$ & $-0.705^{\dagger}(0.205)$ & $0.49(0.33-0.74)$ \\
\hline Nonalcoholic ${ }^{b}$ & $-0.262(0.184)$ & NS \\
\hline \multicolumn{3}{|l|}{ Market characteristics } \\
\hline Percentage minority ${ }^{c}$ & $0.291(0.462)$ & NS \\
\hline White dissimilarity index & $-0.507(0.922)$ & NS \\
\hline Black dissimilarity index & $-0.141(0.372)$ & ns \\
\hline Hispanic dissimilarity index & $-0.398(0.655)$ & NS \\
\hline Percentage $<$ age $12^{d}$ & $-0.93(4.797)$ & NS \\
\hline Percentage ages $12-17^{d}$ & $-0.539(10.307)$ & ns \\
\hline Percentage ages $18-24^{d}$ & $-3.949(7.534)$ & NS \\
\hline Ages $18-24$ years dissimilarity index & $1.32(1.2)$ & NS \\
\hline Annual per capita income & $0.02(0.027)$ & Ns \\
\hline Annual per capita income squared & $-0.0002(0.001)$ & NS \\
\hline Unemployment rate & $0.143^{\dagger}(0.041)$ & $1.15(1.06-1.25)$ \\
\hline $\begin{array}{l}\text { Percentage of the population in an } \\
\text { alcohol control state }\end{array}$ & $-0.07(0.131)$ & NS \\
\hline San Diego & $0.263(0.196)$ & NS \\
\hline \multicolumn{3}{|l|}{ Year } \\
\hline 1995 & Ref. & Ref. \\
\hline 1996 & $0.035(0.041)$ & Ns \\
\hline 1997 & $0.198^{+}(0.065)$ & $1.22(1.07-1.39)$ \\
\hline 1998 & $0.016(0.084)$ & NS \\
\hline 1999 & $-0.014(0.084)$ & NS \\
\hline \multicolumn{3}{|l|}{ Census region } \\
\hline South & Ref. & Ref. \\
\hline Northeast & $-0.059(0.198)$ & Ns \\
\hline West & $-0.057(0.112)$ & NS \\
\hline Midwest & $0.104(0.134)$ & NS \\
\hline \multicolumn{3}{|l|}{ Fit statistic } \\
\hline Adjusted $R^{2}$ & .293 & - \\
\hline
\end{tabular}

Notes: $N=20,098$. Model also contained indicators for beer brand. $\mathrm{OR}=$ odds ratio; $\mathrm{Cl}=$ confidence interval; $\mathrm{NS}=$ not significant at $p<.05 .{ }^{a}$ Reference category for unit size is $72 \mathrm{oz}$; "reference category for beer type is alcoholic, nonmalt liquor: 'reference category for percentage minority is percentage white; ${ }^{d}$ reference category for age groups is age 25 and older. ${ }^{+} p<.01$; no results significant at $p<.05$.
Despite the suggestion in Table 1 of a positive association between some market characteristics and the in-store promotion of beer, we found that promoted sales of beer are not significantly correlated with market-level measures of minority population proportion or spatial distribution within markets, youth population proportion or spatial distribution within markets, income, or state control of the distribution system for beer. We did find a significant positive association between the market unemployment rate and promoted beer sales, with an OR of 1.15 (95\% CI: 1.06-1.25).

To assess the robustness of our results to model specifications and estimation methods, we ran two additional sets of analyses (not reported but available on request). In all cases, the results reported previously for package size were similar in magnitude, sign, and significance. First, the variance estimation method used above accounts for clustering of observations within markets by allowing observations on promoted beer sales to be correlated within each market but uncorrelated across markets. In a separate set of models, in which we did not account for clustering, four of the demographic variables were statistically significant at $p<$ .05 . The percentage of the population in an alcohol control state and the dissimilarity index for whites were significantly negatively associated with promoted beer sales, whereas the dissimilarity index for ages 18-24 and per capita income were significantly positively associated with promoted beer sales.

Second, Figure 1 suggests seasonality in beer promotions, but our multivariate analyses used data from the third quarter only. In a separate set of analyses, we used data from all four quarters by imputing market characteristics using linear interpolation and by setting missing values within a year equal to the value from the third quarter. There were no substantive differences in sign, magnitude, or significance between results using all four quarters of data and those reported above.

\section{Discussion}

Beer is heavily promoted in the United States despite substantial negative social consequences of excessive consumption. Our results show that promoted sales of beer in supermarkets are significantly predicted by package size and type of beer, after controlling for brand, price, marketlevel socioeconomic characteristics, and time. In particular, large-volume packaging appears to be more heavily promoted. On the other hand, socioeconomic variables, such as race/ethnicity, age, and income, are not significant predictors of promoted beer sales. Thus, beer promotions in supermarkets do not appear to target racial and ethnic minorities or youth, either by population proportion or by distribution within market areas.

The results for market characteristics are in general agreement with those of Harwood et al. (2003), who also examined 
the relationship between in-store promotions and community characteristics. Although beer promotions do not appear to target racial or ethnic minorities or youth, our results show that promoted sales of beer in supermarkets are significantly predicted by a market's unemployment rate. This result may suggest that unemployed individuals are more likely to bargain shop or perhaps that beer is promoted more heavily in response to economic downturns.

Our findings are especially salient in light of regulations governing in-store beer promotions. Despite the widespread use of in-store merchandising and promotions in alcohol marketing, there is little federal legislation regulating these practices. The Bureau of Alcohol, Tobacco, and Firearms (BATF) regulates alcohol distribution under the Federal Alcohol Administration Act (Gundlach and Bloom, 1998). According to a 1995 BATF interpretation of the Act, POP promotions are legal as long as manufacturer activities do not threaten retailer independence or act to exclude a competitor (Gundlach and Bloom, 1998). Thus, current federal regulations on in-store merchandising and promotions focus more on protecting free trade than on public health concerns.

State alcohol beverage control agencies also can regulate alcohol advertising in the retail environment. These regulations vary widely by state and local community but may include provisions regarding advertising targeting minors, outdoor advertising near schools or playgrounds, and advertising on college campuses; regulations may also limit the size of advertisements in retail outlets (Center on Alcohol Marketing and Youth, 2003). Lack of state resources hampers development and enforcement of these laws, and manufacturers largely maintain control of how their products are distributed and promoted in retail environments (Alcohol Policies Project, 1997; Gundlach and Bloom, 1998).

Given the relative lack of public health-oriented regulations governing in-store promotions, our finding that largevolume packages of beer have higher odds of being promoted than small-volume packages has major public health implications to the extent that these promotions lead to increased beer consumption, which seems likely. Retail promotions for beer can increase sales substantially (Beverage Industry Magazine, 2001), suggesting that the high rates of promotion seen for 144- and 288-oz packages increase sales of those large-volume packages. Of course, it is possible that individuals who switch from a 6-pack of beer (a 72-oz package) to a 12-pack (a 144-oz package) in response to a promotion buy beer half as often rather than drinking more beer. However, results from the marketing literature suggest that consumer goods packaged in large volumes encourage more product use in a given period than smaller-volume packages (Wansink, 1996). Applied to beer, this implies that, compared with an equivalent number of purchases of 72-oz packages, purchases of 144- and 288-oz packages result in higher beer consumption rather than in less frequent sales. Thus, promotions for 12-packs and cases likely lead to substantially higher aggregate consumption of beer per quarter than would be the case if only 6-packs were promoted or if no promotions occurred at all.

This conclusion is consistent with Kuo et al.'s (2003) results on heavy episodic drinking among college students. The authors found that colleges with higher percentages of off-premise establishments selling large volumes of beer (24-packs, 30-packs, "party balls," and kegs) had higher heavy episodic-drinking rates. Furthermore, about $63 \%$ of the off-premise establishments in their data offered promotions such as volume discounts and advertised price discounts, and these promotions were associated with higher heavy episodic-drinking rates. However, it is possible that college students seek out cheap, large-volume packages with the intent of heavy episodic drinking, rather than engage in heavy episodic drinking because of the availability of largevolume packages of cheap beer. Future research should quantify the excess beer consumption attributable to promoted sales of large-volume packages in a more broadly representative sample.

This study is limited because our data are from supermarkets only and our results may not generalize to other retail channels for beer, such as small grocery stores, liquor stores, and convenience stores. Youth and young adults are more likely to shop in convenience stores or liquor stores (Terry-McElrath et al., 2003), which may explain the lack of significance in our results for youth. Furthermore, the relatively low prevalence of malt-liquor sales and promotions in grocery stores may not be indicative of sales and promotions in other outlets, suggesting caution when trying to draw broader conclusions based on our results. Nonetheless, Harwood et al. (2003) did not find any significant differences between supermarkets and other outlets in the existence of promotions for Budweiser and Miller beer. This implies that the level of promoted beer sales in supermarkets may be comparable to the level of promoted sales in other outlets. In addition, supermarkets are an important outlet for beer, capturing almost as much of the market for beer $(40 \%)$ as convenience stores $(23 \%)$ and liquor stores $(21 \%)$ combined (National Association of Convenience Stores, 2004).

Another important limitation is that our results apply only to beer sales. Previous literature finds significant differences in the demographic characteristics of beer drinkers compared with wine or distilled-spirits drinkers (Kerr et al., 2004; Klatsky et al., 1990). Although beer is the most commonly consumed type of alcohol, when compared with wine or distilled-spirits drinkers, beer drinkers tend to be younger and are more likely to be male. Given the significant demographic differences across drinker types, our results regarding the correlation between beer promotions and age and race/ethnicity should not be viewed as necessarily generalizable to all types of alcohol. 
Despite these limitations, our results show that promoted sales of large-volume packages of beer are more common than promoted sales of smaller-volume packages, and this may be a public health concern. Heavier promotion of largevolume packaging may lead to higher rates of excessive alcohol use and its attendant negative social consequences, although more research is needed to test this conjecture. Our results suggest that the age and racial/ethnic characteristics of market areas are not significant predictors of promoted sales, implying that brewers and distributors do not systematically target minorities and youth with in-store promotions and advertising at the market level.

\section{Acknowledgment}

We thank Susan Murchie for her editorial assistance and the discussion participants at the December 14, 2005, Robert Wood Johnson Foundation Substance Abuse Policy Research Program Annual Grantee Meeting for helpful comments on preliminary analyses.

\section{References}

AL.AnIz, M.L. Alcohol availability and targeted advertising in racial/ethnic minority communities. Alcohol Hlth Res. World 22: 286-289, 1998.

Al.ANIZ, M.L. And WIL.Kes, C. Pro-drinking messages and message environments for young adults: The case of alcohol industry advertising in African American, Latino, and Native American communities. J. Publ. Hith Policy 19: 447-472, 1998.

Alcohol Policies Project. Fact sheet: Young People and Alcohol, 1997. Washington, DC: Center for Science in the Public Interest, 2002 (available at: http://www.cspinet.org/booze/liquor_branded_advertising_FS2 .htm).

Alcohol. Policy Information System (APIS). Alcohol Policy Information System (available at: http://alcoholpolicy.niaaa.nih.gov), 2005.

Beverage Industry Magazine. POP Proves Its Worth, July 2001.

Bureau of the Census. 1990 to 1999 Annual Time Series of County Population Estimates by Age, Sex, Race, and Hispanic Origin, Washington, DC: Department of Commerce, 2000. (available at: http:// www.census.gov/popest/archives/1990s/CO-99-12.html).

Bureau of Economic Analysis. CA1-3: Personal Income, Population, Per Capita Personal Income - Personal Income Summary Estimates; 3.0: Per Capita Personal Income; All States 1995-1999, Washington, DC: Department of Commerce, 1995-1999 (available at: http://www.bea.gov/ bea/regional/reis).

Bureau of Labor Statistics. Historical SIC Basis Data from the Quarterly Census of Employment and Wages, All States, All Counties 1995. 1999 (available at: www.bls.gov/cew)

Center on Alcohol. Marketing and Youth. State Alcohol Advertising Laws: Current Status and Model Policies, Washington, DC: Georgetown University (available at http://camy.org/research/statelaws0403), 2003,

Federal Trade Commission (FTC). Self-Regulation in the Alcohol Industry: A Review of Industry Efforts to Avoid Promoting Alcohol to Underage Consumers, Washington, DC: Federal Trade Commission. 1999 (available at: http://www.ftc.gov/reports/alcohol/alcoholreport).

GreENE, W.H. Econometric Analysis, 3rd Edition, Upper Saddle River, NJ: Prentice Hall, 1997.

GundLach, G.T. AND BloOM, P.N. Slotting allowances and the retail sale of alcohol beverages. J. Publ. Policy Market, 17: 173-184, 1998.

Hackbarth, D.P., Silvestri, B., and Cosper, W. Tobacco and alcohol billboards in 50 Chicago neighborhoods: Market segmentation to sell dangerous products to the poor. J. Publ. Hlth Policy 16: 213-230, 1995.
Harwood, E.M., Erickson, D.J., Fabian, L.E., Jones-Webb, R., Slater, S., AND ChaloupKa, F.J. Effects of communities, neighborhoods and stores on retail pricing and promotion of beer. J. Stud. Alcohol 64: 720-726, 2003.

INFORMATION RESOURCES INCORPORATED (IRI). InfoScan Reviews: Grocery Channel, Beer and Malt Beverages Category, 64 Market Report, 19951999, Chicago, IL: Information Resources Inc., 2000.

Kerr, W.C., Greenfield, T.K., Bond, J., Ye, Y., and Rehm, J. Age, period and cohort influences on beer, wine and spirits consumption trends in the US National Alcohol Surveys. Addiction 99: 1111-1120, 2004

Klatsky, A.L., Armstrong, M.A., And KIPP, H. Correlates of alcoholic beverage preference: Traits of persons who choose wine, liquor or beer. Brit. J. Addict. 85: 1279-1289, 1990.

Kuo, M., Wechsler, H., Greenberg, P., and Lee, H. The marketing of alcohol to college students: The role of low prices and special promotions. Amer. J. Prev. Med. 25: 204-211, 2003.

McGinnis, J.M. AND FoEge W.H. Actual causes of death in the United States. JAMA 270: 2207-2212, 1993.

MADDALA, G.S. Limited-Dependent and Qualitative Variables in Econometrics, New York: Cambridge Univ. Press, 1983.

Massey, D.S. and Denton, N.A. The dimensions of residential segregation. Social Forces 67: 281-315, 1988.

Midanik, L.T., Chaloupka, F.J., Saitz, R., Toomey, T.L., Fellows, J.L., Dufour, M., Lander, M., Brounstein, P.J., Stahre, M.A., Brewer, R.D., NAImI, T.S., AND MiLler, J.W. Alcohol-attributable deaths and years of potential life lost-United States, 2001. MMWR 53 (37): 866-870, 2004.

Mokdad, A.H., Marks, J.S., Stroup, D.F., and Gerberding, J.L. Actual causes of death in the United States, 2000. JAMA 291: 1238-1245, 2004.

National Alcohol Beverage Control Association (NABCA). National Alcohol Beverage Control Association, Alexandria, VA (available at: http://www.nabca.org), 2005.

National. Association of Convenience Stores. 2004 SOI Highlights: The Convenience Store Industry's 2003 Performance, Alexandria, VA: National Association of Convenience Stores, 2004 (available at: www.nacsonline.com).

National Institute on Alcohol Abuse and Alcoholism. Eighth Special Report to the U.S. Congress on Alcohol and Health, NIH Publication No. 94-3699, Bethesda, MD: Department of Health and Human Services, 1994.

National Institute on Alcohol Abuse and Alcoholism. Tenth Special Report to the U.S. Congress on Alcohol and Health: Highlights from Current Research, NIH Publication No. 00-1583, Bethesda, MD: Department of Health and Human Services, 2000.

Scribner, R., Cohen, D., Kaplan, S., and Allen, S.H. Alcohol availability and homicide in New Orleans: Conceptual considerations for small area analysis of the effect of alcohol outlet density. J. Stud. Alcohol 60: $310-316,1999$.

SCribner, R.A., MacKinnon, D.P., And DWyer, J.H. The risk of assaultive violence and alcohol availability in Los Angeles county. Amer. J. Publ. Hith 85: 335-340, 1995.

Terry-McElrath, Y.M., Harwood, E.M., Wagenaar, A.C., Slater, S., Chaloupka, F.J., Brewer, R.D., and Naimi, T.S. Point-of-purchase alcohol marketing and promotion by store type-United States, 20002001. MMWR 52 (14): 310-313, 2003.

Wansink, B. Can package size accelerate usage volume? J. Mark. 60 (3): 1-14, 1996.

Weitzman, E.R., Folkman, A., Folkman, M.P., and Wechsler, H. The relationship of alcohol outlet density to heavy and frequent drinking and drinking-related problems among college students at eight universities. Hlth Place 9: 1-6, 2003a.

Weitzman, E.R., Nelson, T.F., and Wechsler, H. Taking up binge drinking in college: The influences of person, social group, and environment. J. Adolesc. Hith 32: 26-35, $2003 \mathrm{~b}$.

Zhu, L., Gorman, D.M., And Horel, S. Alcohol outlet density and violence: A geospatial analysis. Alcohol Alcsm 39: 369-375, 2004. 